\begin{tabular}{|c|c|c|}
\hline $\begin{array}{l}\text { A. } \\
\text { PUCRS }\end{array}$ & $\begin{array}{l}\text { ESCOLA DE } \\
\text { HUMANIDADES }\end{array}$ & $\begin{array}{l}\text { Revista de Cultura e Literaturas de Lingua Portuguesa } \\
\text { Navegações, Porto Alegre, v. 15, n. 1, p. 1-10, jan.-dez. } 2022 \\
\text { e-ISSN: 1983-4276 ISSN-L: 1982-8527 }\end{array}$ \\
\hline (d) $h t \mathrm{tp}: / / \mathrm{dx}$ & $\mathrm{org} / 10.15448 / 1983-4276.2022 .1 .41912$ & \\
\hline
\end{tabular}

SEÇÃO: DOSSIÊ

\title{
Labirintos identitários em Todos os nomes, de Saramago
}

The identity labyrinths in All the names, by Saramago

\section{Marcos Lúcio de Sousa \\ Góis $^{1}$}

orcid.org/0000-0003-0328-1509

mlsgois2008@uol.com.br

\section{Noraci Cristiane Michel \\ Braucks ${ }^{1}$ \\ orcid.org/0000-0002-8065-1115} cristianebraucks@hotmail.com

Recebido em: 10 nov. 2021. Aprovado em: 14 dez. 2021. Publicado em: 8 mar. 2022.

\section{(c) (1)}

Artigo está licenciado sob forma de uma licença Creative Commons Atribuição 4.0 Internacional.
Resumo: Este trabalho problematiza a construção de identidades nestes tempos contemporâneos a partir de uma leitura do romance Todos os nomes, de José Saramago, pelo prisma teórico-metodológico dos estudos discursivos e culturais, centrando a discussão no personagem Sr. José. Este é um exercício analítico cujo desejo é contribuir para as discussões a respeito da relação entre discurso, literatura e identidade na chamada (pós)modernidade. Discutir "identidade" é também levantar pontos sobre "sujeito", "subjetividade", "história", dentre outros termos nucleares a esse campo de estudo. O presente artigo, com base de modo especial em Stuart Hall e Zygmunt Bauman, inicia um percurso em busca por respostas para quem são os "anônimos" (ou Zés) na (pós)modernidade e como se constroem suas próprias significações na contemporaneidade. Fazem-se aqui perguntas; levantam-se algumas respostas.

Palavras-chave: Discurso. Pós-modernidade. Literatura. Identidade.

Abstract: This work problematizes the construction of identities in the contemporary times from a reading of the novel Todos os nomes, by José Saramago, through the theoretical-methodological discursive and cultural studies perspectives, centering the discussion on the character Sr. José. This is an analytical exercise whose desire is to contribute to discussions about the relationship between discourse, literature and identity in the so-called (post)modernity. Discussing "identity" is also raising points about "subject", "subjectivity", "history", among other terms that are core to this field of study. This paper, based in a special way on Stuart Hall and Zygmunt Bauman, starts a journey in search of answers for "who" the "anonymous" are (or Zés) in (post)modernity and how they are meant in contemporaneity. Questions are asked here; some answers are raised.

Keywords: Discourse. Post-modernity. Literature. Identity.

"[...] de facto não há nada que mais canse uma pessoa que ter de lutar, não com o seu próprio espírito, mas com uma abstracção".

(Narrador, Todos os nomes)

\section{Introdução}

Os Estudos de Discursos e Culturais configuram-se em campos do saber vastos e heterogêneos, nos quais teoria e análise caminham de tal modo imbricadas que é dificil, senão impossivel, fazer leituras sem estabelecer, de saída, um aporte teórico-metodológico que sustente os sentidos produzidos pelo ato de ler. Se não existem sentidos dados a priori, podemos apenas falar em dados sentidos, em construção/atribuição de sentidos, mostrando uma relação muito estreita entre sujeitos, textos e sentidos. Nessa linha, os estudiosos de discursos não se satisfazem 
em mobilizar "noções tomadas à Psicanálise, à Sociologia, à Antropologia etc. para 'aplicá-las' a textos literários: não se trata de projetar um universo (as ciências humanas) noutro (a literatura) que the seria estranho, mas de explorar o universo do discurso" (MAINGUENEAU, 2006, p. 38). Portanto, para que possamos atingir nosso objetivo, problematizar a identidade na chamada pós-modernidade pela voz e consciência de um personagem e de seu narrador, mobilizamos nesta reflexão alguns estudiosos, dando relevo a Stuart Hall e Zygmunt Bauman, para tentar compreender o esconde-esconde de "identidades" presente em Todos os nomes (SARAMAGO, 2007), publicado inicialmente em 1997 pela editora Caminho, de Portugal, lendo o romance como um índice importante para compreender nossa própria contemporaneidade.

No romance Todos os nomes (SARAMAGO, 2007), conhecemos certa trajetória do personagem Sr. José, um funcionário antigo do fictício Conservatória Geral do Registro Civil, cujo nome pessoal (José) é a própria manifestação da "insignificância da personagem" (SARAMAGO, 2007, p. 17). Por possuir o hábito de colecionar recortes a respeito de pessoas famosas que nasceram na cidade, certo dia Sr. José decide incrementar as informações de sua coleção, buscando "clandestinamente" por fichas nos arquivos do Conservatória. Nessa busca, cai-lhe das mãos uma; o nome ali registrado não the é conhecido e, logo, lhe diz pouco. Por causa dessa quase ausência de informação, o protagonista decide tirar aquela pessoa do anonimato e inicia uma "saga" em busca da história por trás do nome e acaba erigindo, em uma trajetória em espiral, os contornos da própria história. O pacato e servil funcionário público se depara com situações nas quais jamais se imaginara envolvido, tomando decisões que não parecem combinar com sua natureza, com sua identidade, seu ethos. O desfecho surpreende e traz à tona questões existenciais profundas, em seus marcos mais inquietantes: o desenrolar de um novelo de vida e de morte.

Parece-nos relativamente tranquilo que a complexidade do romance de Saramago permita ao leitor empreender distintos projetos de leitura, e escolhemos o problema da identidade. E o motivo é simples: o título Todos os nomes provocou-nos ao primeiro olhar; ao final, a ausência de outros nomes no romance, excetuando o do protagonista, contribuiu para essa inquietação inicial. Ilustrativa é a passagem na qual o narrador, embora reconheça que também José tem sobrenome,

\begin{abstract}
nunca the serviu de nada pronunciar o nome completo, uma vez que os interlocutores só retêm na memória a primeira palavra dele. José, a que depois virão a acrescentar, ou não, dependendo do grau de confiança ou de cerimónia, a cortesia ou a familiaridade do tratamento (SARAMAGO, 2007, p. 17).
\end{abstract}

No texto não há, portanto, cortesia. Nem "familiaridade do tratamento". Exceto, claro, pelo uso do pronome de tratamento "Sr.", que acompanha "José" ao longo da trama e, "Que, [no entanto], diga-se já, não vale o de senhor tanto quanto em principio pareceria prometer [...]" (SARAMAGO, 2007, p. 18). Assim, o enunciado "todos os nomes" corresponde, na verdade, a nome (quase) nenhum. O único citado na obra é, conforme dissemos, o de nosso herói, Sr. José - nome tão ordinário que é inevitável não o remeter ao lugar comum, aquele que não é absolutamente desconhecido, nem totalmente conhecido: além de muitos homens serem chamados José, em português brasileiro são apelidados "Zé", uma abreviação que confere, a seu detentor, uma generalidade, e não necessariamente uma identidade. Há, portanto, neste romance de Saramago, toda uma reflexão que coloca em xeque a própria noção de "eu" e de "identidade" e que, assim, merece nossa adesão, zelo e dedicação.

Maria Paranhos sintetiza essa correlação na experiência vivencial do personagem Sr. José do seguinte modo:

José é um homem simples como o seu nome,
que é tão comum como ele próprio. Um nome
só e um homem só, que poderia ser só ele ou
todos os homens, todos os "Josés", que vivem
um cotidiano desinteressante e repetitivo,
dentro de um mundo opressor e determinista
como o é a Conservatória Geral do Registro
Civil, grande arquivo dos vivos e dos mortos,
onde o auxiliar de escrita - também protago- 
nista deste romance - trabalha mediocremente (PARANHOS, 2009, p. 101).

A natureza própria da pessoa investigada pelo personagem Sr. José corresponde, na trama, à maneira como vive essa pessoa. Ele conhece, pela ficha, alguns dados, como gênero (mulher), o nome (não revelado), a idade e o endereço. Sabe também que foi casada e que está, até onde sabe, divorciada. Entretanto, quer saber mais, para além da aparente objetividade: se é feliz, se é bonita, se é mãe... A situação complica quando o protagonista chega ao endereço informado na ficha e, surpreso, descobre que a mulher não mora naquele lugar há tempos. O personagem passa, então, a enredar os fios de informações coletadas de uma senhora, madrinha da mulher do fichário.

Em Todos os nomes (SARAMAGO, 2007), os "nomes" fazem emergir um fato intrigante: eles são de conhecimento do Sr. José, todos eles, devido ao acesso que tem dos registros de nascimento e de óbito conservados nos arquivos da Conservatória Geral. Entretanto, esses nomes não são revelados na trama. Por quê? Há trabalhos que dão resposta a essa questão, como o de Flach (2006). Para a autora, sendo o nome uma convenção, "sob a qual se esconde um intenso desejo de ser" (FLACH, 2006, p. 13), então, não há outros nomes porque é ao próprio Sr. José que se busca essencialmente conhecer. ${ }^{2}$

Embora a hipótese defendida por Flach seja interessante, neste artigo, tentamos uma abordagem ligeiramente diferente: defendemos que o sentido ao redor do "nome" é, no romance, elemento tão importante a ponto de se tornar uma sintese de nossos dias: a questão da "identidade" é o cerne de várias e (in)tensas situações discursivas atuais. O problema do "nome" no romance de Saramago marca justamente uma complexa problematização do próprio "eu" (pós)moderno. ${ }^{3}$ Antes de apresentarmos esse ponto de vista, cabem algumas palavras sobre o conceito de "identidade", sem a pretensão de construirmos um estado da arte.

\section{Identidade e (pós)moderno}

Enquanto questão identitária, ${ }^{4}$ trazida à tona na literatura, interessa-nos, em especial, a condição social ordinária, ${ }^{5}$ representada na obra pelo personagem, e as relações do sujeito (pós)moderno com essa condição. Por isso, a hipótese em relevo é que Sr. José carrega aspectos do sujeito (pós) moderno, cuja identidade está indefinida... fluida... desmanchando-se no ar; sendo descontruida e reconstruida à medida que a própria existência vai-se desenhando. E o esforço do personagem em tornar "sólida" sua própria existência o impulsiona a construir a história real da mulher desconhecida, o que nos leva a questionar a própria solidez identitária do protagonista. Essa situação dialética de buscar o outro e encontrar a si mesmo, ou buscar o "eu" no "outro", está marcada, em Todos os nomes, especialmente, por dois aspectos já destacados por Flach (2006): aquilo que é próprio do social moderno, ou seja, as identidades, os endereços, as funções fixas; e o que é essencial, o que de fato importa à vida: a flexibilização, a flutuação, a incerteza, o trânsito.

Alguns teóricos contemporâneos têm levantado pontos a respeito da identidade nesse período entre o final do século passado e o XXI. Entre eles, destacamos dois: Stuart Hall, em

\footnotetext{
2 Em As intermitências da morte, há um diálogo entre o "espírito que pairava sobre a água" e o "aprendiz de filósofo" a respeito da palavra "metamorfose", servindo para ilustrar a defesa que fazemos aqui: "[...] Chama-se metamorfose, toda a gente sabe de que se trata, disse condescendente o aprendiz de filósofo, Ai está uma palavra que soa bem, cheia de promessas e certezas, dizes metamorfose e segues adiante, parece que não vês que as palavras são rótulos que se pegam às cousas, não são as cousas, nunca saberás como são as cousas, nem sequer que nomes são na realidade os seus, porque os nomes que lhes deste não são mais do que isso, os nomes que lhes deste" (SARAMAGO, 2005, p. 78, grifo nosso). No caso de Todos os nomes, é contra essa "condescendência" ontológica que vai se urdindo a trama de Sr. José, talvez sem sucesso. Voltamos ao tema adiante.

3 Adotamos neste trabalho a grafia "(pós)moderno" (e suas variantes), e não moderno e/ou pós-moderno, no sentido de marcarmos de que estamos tratando de um tempo-espaço ainda impreciso teoricamente. Não é moderno, certamente, mas também não deixa de ser; não é pós-moderno, sendo. Estamos em um momento de transição, de enfrentamentos, de redefinições (SANTOS, 1996, 2002, 2003).

4 Assumimos aqui a noção de identidade apresentada por Stuart Hall (2006), para quem o conceito de identidade não poder ser tomando como estando preso à ideia de "identidade fixa", mas, sim, como sendo ela o resultado de diferentes identidades, por vezes contraditórias, que se alternam sem situações diferentes para construir os sujeitos (pós)modernos.

5 Relacionemos aqui "condição social ordinária" com a "condição comum" de tantos, que se aproxima (ou até mesmo representa) da inexpressividade social os Zés, conforme mencionamos na Introdução.
} 
Identidade cultural na pós-modernidade (2006), e Zygmunt Bauman, Identidade (2005). Esses estudiosos apresentam uma aporia essencial da problemática da identidade (pós)moderna, a saber, a existência fragmentada do "outro" e o desaparecimento/diluição do "eu" enquanto sujeito social fixo.

Hall apresenta, além de discussões sobre a identidade no que ele chama de "pós-modernidade", duas outras questões que se fazem relevantes ao objetivo por nós proposto. A primeira diz respeito ao descentramento ou fragmentação do sujeito. Ou seja, a unidade estável, o sujeito cartesiano do cogito, ou mesmo o sujeito cristão da Idade Média - ao qual se dedicou Le Goff (1989) -, como foi descrito pelo pensamento moderno, não se sustenta mais diante das mudanças estruturais da sociedade (pós)moderna. As referências, desde Freud e Lacan, acerca de linguagem, gênero, cultura, sexualidade, etnia, raça, nacionalidade não são mais estanques, nem uniformes - ganha lugar a noção de individualidade. Gross dirá que Foucault também contribui significativamente para esta problematização, por tratar de "identidade como forma da questão" (GROSS, 1995, p. 178), ou "problema", como lemos em autores como Hall e Bauman, e a estes dois nos dedicamos. E isso pela razão de que a especificidade do indivíduo, como estes dois discutem, tem sido compreendida como algo formado, essencialmente diante do "espelho" do outro - distanciando-se da ideia de um padrão identitário inato, ou pré-existente ao nascimento. Por isso,

[...] em vez de falar de identidade como uma coisa acabada, deveriamos falar de identificação, e vê-la como um processo em andamento. A identidade surge não tanto da plenitude da identidade que já está dentro de nós como individuo, mas de uma falta de inteireza que é "preenchida" a partir de nosso exterior, pelas formas através das quais nós imaginamos ser visto pelos outros (HALL, 2006, p. 39, grifo do autor).

Esse processo de "identificação" constante, essa busca por "preenchimento", é elemento importante na obra em relevo de Saramago, sendo, na narrativa, marcante, reforçada pela permanente ideia de construção, de "processo em andamento", ou mesmo pela necessidade de não identificação: "Sendo conhecido na casa não precisaria de apresentar o cartão de identificação que o acreditava como funcionário do Registro Civil" (SARAMAGO, 2007, p. 219). O protagonista ao longo da trama vai completando os espaços de seu labirinto, ao mesmo tempo em que outros vazios vão aparecendo.

Bauman (1998) diz que, embora sua produção possa estar relacionada a produtores que pensam a (pós)modernidade, o "pós" aí não significa "fim", talvez uma liquefação. No livro Identidade (2005) e, pelo menos, em Modernidade Liquida (2001), Bauman discute esse conceito pela perspectiva das ciências sociais, reforçando os aspectos liquefeitos da (pós)modernidade. Por exemplo, no livro que resultou de entrevista dada ao jornalista italiano Benedetto Vecchi, Bauman (2005) centra parte de suas discussões, para falar de identidades, em torno do verbo "pertencer", mostrando, por meio de exemplos destacados do contexto político, social, cultural, que a questão da "identidade" (dizer "eu") não é trivial no mundo contemporâneo. Para o autor, com a emergência do Estado Moderno, pela fragmentação do sistema feudal, houve uma "crise de pertencimento", afinal, pertencer a uma nação cuja "soberania territorial" foi o resultado de uma convenção humana não era algo simples de se aceitar e parece que, em contextos mais recentes envolvendo deslocamentos (simbólicos e/ou físico), ainda não é.

Para Bauman, a relação entre identidade e pertencimento é poderosa tendo em vista que estão ligados por sua "finitude". Em outros termos, a criação dos estados-nação contribuiu para que o sujeito moderno aprimorasse cada vez mais sua percepção de que possui qualidades políticas, sociais, biológicas etc., que o fizeram ou, melhor, o fazem transitar (dai "identidade em trânsito") entre lugares. Em outros termos, a modernidade complexificou as relações humanas (eu-tu), complexificando também os lugares por onde caminham os indivíduos humanos. Se o indivíduo possui, hoje, maior facilidade para 
transitar entre lugares de sujeitos, ao fazer isso, por causa da instabilidade nos principios-base de nossa sociedade, como saber o que é um valor eticamente positivo, o individuo corre mais riscos de apresentar fissuras em sua identidade supostamente objetiva, levando o sujeito a crises no modo subjetivo como se vê no mundo, algo mais raro de acontecer, por exemplo, na Idade Média (LE GOFF, 1989), tempo em que as relações e os lugares humanos eram relativamente mais estáveis do ponto de vista das identidades. Nós, indivíduos, desde há tempos buscamos um lugar estável para colocar os pés: um lugar religioso, um lugar político, um lugar familiar etc. O problema de nosso tempo, "problema" não em seu sentido comumente negativo, e que nos leva a frequentes "crises de identidade", é que esses "lugares" não são tão estáveis como em outros tempos ou como nós os imaginamos.

Em outro livro, Modernidade Liquida, Bauman (2001) divide a modernidade em duas, o que nos ajuda a entender sua concepção de identidade: uma sólida e outra líquida. Se, na primeira, aos indivíduos cabia certa definição de identidade a partir de uma concepção fixada pela noção de estabilidade (de região, de nascimento, de familia, de grupo social etc.); na modernidade líquida, a identidade tornou-se o resultado da construção que o indivíduo faz via um conjunto de valores de grupos com os quais ele dialoga, convive, interage e, nem sempre, de modo amistoso, cordial, fraterno. Se, no passado ao qual o autor se refere, a identidade era, digamos, uma forma de herança: uma vez filho de César, sempre filho de César; hoje, cada vez mais, e graça às rupturas provocadas pela (pós)modernidade, identidade é aquilo que resulta de uma criação em permanente transformação. Dito de outro modo: "[...] a 'identidade' só nos é revelada como algo a ser inventado, e não descoberto; como alvo de um esforço, 'um objetivo'; como uma coisa que ainda se precisa construir a partir do zero ou escolher entre alternativas e então lutar por ela e protegê-la [...]" (BAUMAN, 2005, p. 21-22, grifo do autor). Identidade é, logo, (também) estar, e não (apenas) ser. Vale a pena reforçar aqui: Sr. José tem "um objetivo", que o faz deslocar-se, mover-se, e não apenas no espaço, mas também no tempo.

Bauman e Hall estão, para concluir essas notas expositivas, no rol daqueles autores que colocam, ao pensar as sociedades contemporâneas, a questão da "identidade" no centro dos debates. Se há poucas décadas a "identidade" talvez não passasse de um objeto de reflexão filosófica, como diz Bauman (2005), em nossa atualidade ela é o "papo do momento": "um assunto de extrema importância e evidência" (BAUMAN, 2005, p. 23).

No próximo item, mostramos uma leitura do livro de Saramago com o olhar na sumarização teórica que acabamos de fazer, procurando identificar o funcionamento desse certâmen (pós) moderno sobre identidades no romance Todos os nomes.

\section{O nome}

Como já expusemos, a ausência de nomes no romance Todos os nomes é de relevo ímpar na obra. Negar a importância da nominação pontua justamente o questionamento a respeito de quem é o "eu" por trás do nome. Podemos pensar, desta forma, que o narrador e o personagem de Sr. José compartilham da tarefa de investigar o que há antes do nome, aquele momento de tensão entre as palavras e as coisas. Assim, não se trata de buscar o que estaria escondido às costas da "palavra", mas da "coisa" a quem se dá, se deu ou se dará um nome, que só se conhece à semelhança de estilhaços de um espelho. Não é justamente essa a questão essencial da identidade (pós)moderna? A trajetória existencial do sujeito (pós)moderno não estaria centrada na reafirmação permanente da subjetividade, quer dizer, na identidade como uma questão em construção?

João de Pina Cabral, citando Adriano Naves de Brito, percebe ainda a complexidade da relação da nominação com o conhecimento daquilo ou daquele que se pretende nominar: "Para ser bapitzado, um objecto tem que estar suficientemente distinguido na multiplicidade dos dados da percepção. Não se pode baptizar um objecto para o qual não haja clareza sobre sua identidade" (BRITO apud CABRAL, 2008, p. 8). A escolha de 
nomes próprios tem sido relacionada ao contexto social das familias no ato de nomear seus filhos. Como é uma nominação que antecede o conhecimento do nominado, é comum que mais tarde uma alcunha se torne o identificador nominativo dos individuos. Por exemplo, pelo hipocorístico ou por um complemento, como em "Fernandinho" para diferenciar a criança do avô "Fernando", ou "João da Farmácia", para especificar o fator referencial de uma figura conhecida em determinado contexto. ${ }^{6}$ Numa conferência enriquecedora sobre a relação nome e identidade, Soler (2007, p. 173-174), ao reler Lacan, diz o seguinte:

O nome próprio designa o que de um ser não está identificado e não é identificável pelo significante. Se o sujeito é identificado pelos significantes que assume, estes, contudo, são apenas representantes que não dizem o que ele é, digamos assim, em si mesmo, fora da representação. Resta então um x. O nome próprio não é precisamente um significante que representa o sujeito, mas índice do que há nele de "impensável", daquilo que é dele, mas não passa no significante.

E "[...] o Sr. José também tem apelidos [...]" (SARAMAGO, 2007, p. 17), como veremos. Um nome familiar, herdado do pai e da mãe, que lhe é atribuido por herança e que faz parte de sua história: "daquilo que é dele, mas não passa no significante". Porém, como esse sobrenome não é dado a conhecer ao leitor, inferimos que esse passado, essa herança de nome, não importa; encontra-se ai silenciado. Importa o presente, o percurso do personagem em busca de conhecer-se.

Em determinado momento do Livro Terra à vista, Eni Orlandi fala do "silêncio constitutivo", quando discute a "nomeação": "a atividade de nomear é bem ilustrativa: toda denominação circunscreve o sentido do nomeado, rejeitando para o não-sentido tudo o que nele não está dito" (ORLANDI, 1990, p. 49). De fato, para que Sr. José consiga fazer-existir o outro, no caso, a mulher desconhecida, ou fazer-existir-se nela, dar-lhe uma existência, precisa atribuir um corpo com- plexo e completo ao nome, corporificar o objeto substantivo. Atribuir sentido, em suma, situando esse corpo em um tempo e em um espaço, é construir-lhe uma história:

Em nenhuma das ocasiões anteriores, porém, tinha experimentado a impressão real, objectiva, tão física como uma súbita contracção muscular, da efectiva impossibilidade de medir esse tempo a que poderíamos chamar da alma, como no momento em que, já em casa, olhando uma vez mais a data do falecimento da mulher desconhecida, quis, vagamente, situá-la no tempo que decorrera desde que principiara a procurá-la (SARAMAGO, 2007. p. 178).

Ao fazer isso, ao buscar construir a história da "mulher desconhecida", silencia outras tantas possibilidades reais, simbólicas, imaginadas. No entanto, a estrutura narrativa do romance elide esse exercício de nominação, que ocorre, não ocorrendo. O próprio título da obra de Saramago é a manifestação de que "todos os nomes" anula a possibilidade de conhecer, cuja conclusão inevitável se concretiza neste enunciado: "Desculpe, enganei-me, vinha à procura doutra pessoa" (SARAMAGO, 2007, p. 51).

Nessa perspectiva, aproximamo-nos da noção de linguagem enquanto fenômeno que apreende e estrutura a existência: "Os acontecimentos do mundo só ganham sentido por meio da estruturação que lhes é dada pelo próprio ato da linguagem e de sua tematização, o qual se inscreve numa intenção comunicativa". (CHARAUDEAU apud GUILHAUMOU, 2009, p. 188). Quer dizer, ao nominar objetos, sujeitos ou acontecimentos, o sujeito não age apenas externamente, falando sobre algo que existe. Age essencialmente gerando aquilo que passa a ser. A isso poderia corroborar a compreensão de Sylvian Auroux (1998), para quem "não existe uma ordem separada da linguagem e menos ainda uma faculdade humana específica para a linguagem: 'o mundo faz parte da definição da linguagem'" (AUROUX apud GUILHAUMOU, 2009, p. 198). Entendemos que, ao nomear, o indivíduo conecta o real e o

\footnotetext{
6 Cabral (2008) apresenta ainda outros aspectos a respeito dos nomes pessoais, especialmente, em lingua portuguesa: a relevância do nome nas interações interpessoais - a maneira como um individuo é interpelado, está marcada pela forma como é identificado (seu nome) socialmente.
} 
aparente (o que é dito sobre o real), a realidade e o discurso, de maneira que não é mais possivel separar - embora seja possivel distinguir - o que è do nome que the é atribuido.

A busca do Sr. José assemelha-se a esse processo primordial do ato nominador. A pergunta do homem comezinho, diluido na imensidão da massa social, é por alguma coisa que vem antes da nominação, ou seja, da conclusão do processo atributivo de significado (GUILHAUMOU, 2009). Esse processo é um percurso complexo, cujo transcorrer corresponde justamente à (re)construção dos traços singularizantes que distinguem um ser específico do geral - a individualidade, a subjetividade. Assim, o Sr. José de Todos os nomes precisava chamar-se Sr. José para ser, ele próprio, o representante de uma vida comum: "Além do seu nome próprio de José, o Sr. José também tem apelidos, dos mais correntes, sem extravagâncias onomásticas, um do lado do pai, outro do lado da mãe" (SARAMAGO, 2007, p. 17), "apelidos" ou "sobrenomes" que, ao final, não adquirem relevo. Existem, não existindo. E o nome? É tão comum que bem poderia ser outro, sem muitas perdas, como Manuel (Mané) ou Joaquim (Quin), a ponto de não ser possivel precisar a individualidade passada do personagem; apenas a criada no percurso narrativo. De fato, iniciamos a leitura sabendo seu nome, mas o conhecemos tanto quanto um dos muitos "Zés" - sujeitos de vida cotidiana - que nos cercam: "insignificantes", mas como com uma forte vontade de ser. Os demais personagens, todos inominados, embora presentificados em uma narrativa extemporânea, também não recebem nomes para reforçar o argumento de que o conceito de identidade é contingencial:

Na linguagem do senso comum, a identificação é construída a partir do reconhecimento de alguma origem comum, ou de características que são partilhadas com outros grupos ou pessoas, ou ainda a partir de um mesmo ideal. [...]. Embora tenha suas condições determinadas de existência, o que inclui os recursos materiais e simbólicos exigidos para sustentá-la, a identificação é, ao fim e ao cabo, condicional; ela está, ao fim e ao cabo, alojada na contingência. Uma vez assegurada, ela não anulará a diferença (HALL, 2007, p. 106).
Mesmo os personagens famosos da coleção do Sr. José estão inominados, talvez porque a fama não seja suficiente para serem verdadeiramente conhecidos: "Reparando bem, a vida delas é sempre igual, nunca varia, aparecem, falam, mostram-se, sorriem para os fotógrafos, estão constantemente a chegar ou a partir [...]" (SARAMAGO, 2007, p. 194). Ao contrário dessa conclusão a que chega em relação às celebridades, o Sr. José se convence de que a vida de alguém desconhecido pode ser, afinal, bastante interessante. Assim e por essa lógica exclusiva, buscar pela mulher desconhecida the faz sentido. Procura que confere ao protagonista um lugar outro, para além das paredes frias da Conservatória, onde apenas nomes sem história, datas e números importam:

[...] à Conservatória só interessa saber quando
nascemos, quando morremos, e pouco mais, Se
nos casámos, se nos divorciámos, se ficámos
viúvos, se tornámos a casar, à Conservatória
é indiferente se, no meio de tudo isso, fomos
felizes ou infelizes, A felicidade e a infelicidade
são como as pessoas famosas, tanto vêm como
vão, o pior que tem a Conservatória Geral é não
querer saber quem somos, para ela não pas-
samos de um papel com uns quantos nomes e
umas quantas datas (SARAMAGO, 2007, p. 196).

No sentido do que o nome é e representa, deparamo-nos com questões acerca do lugar do autor no enunciado literário. Assim, conforme observa Cabral: em Marcel Proust, os nomes são sempre significativos; em Guimarães Rosa, os nomes dos personagens têm sido compreendidos com significados universais; em Saramago, em Todos os nomes, deixam-se pistas a respeito da identidade do protagonista (CABRAL, 2008, p. 9-10). A narrativa, porém, tanto reforça como desestrutura a impressão inicial sobre o personagem Sr. José. A obra de Saramago aprofunda, em muito, a questão do significado por trás do nome, à medida que apresenta a inquietação do protagonista que se assume em uma posição de individuo comum, insignificante, conforme mostramos

No romance, a angústia diante da possibilidade de ter resolvido o enigma da mulher desconhecida é lapidar, nevrálgico no sentido de mostrar 
a constante inquietação de Sr. José, como observamos nesta citação mais longa:

Despertou-o uma ideia inesperada que the irrompeu no meio do sono, de um modo tão fulminante que nem deu tempo a que um sonho se tecesse com ela, a ideia de que talvez a mulher desconhecida, a do verbete, fosse, afinal de contas, aquela que ele ouvira a embalar a criança, a do marido impaciente. nesse caso a sua busca teria terminado, estupidamente terminado, no próprio momento em que deveria começar. Uma angústia súbita apertou-lhe a garganta enquanto a razão afligida tentava resistir, queria que ele mostrasse indiferença, que dissesse, Melhor assim, menos trabalho me dará, mas a angústia não desistia, continuava a apertar, a apertar, e agora era ela que estava a perguntar à razão, E que vai ele fazer, se já não pode realizar o que pensou, Fará o que sempre fez, recortará recortes de jornais, fotografias, notícias, entrevistas, como se não tivesse sucedido nada, Coitado, não acredito que o consiga, Porquê, A angústia, quando chega, não se vai embora com essa facilidade, Poderá escolher outro verbete e ir à procura dessa pessoa, $\mathrm{O}$ acaso não escolhe, propõe, foi o acaso que the trouxe a mulher desconhecida, só ao acaso compete ter voto nesta matéria, Não lhe faltam desconhecidos no ficheiro, Mas faltam-lhe os motivos para escolher um deles, e não outro, um deles em particular, e não um qualquer de todos os outros, Não creio que seja uma boa regra de vida deixar-se alguém guiar pelo acaso, Boa regra ou não, conveniente ou não, foi o acaso que the pôs nas mãos aquele verbete, E se a mulher for a mesma, Se a mulher for a mesma, então o acaso foi esse, Sem outras consequências, Quem somos nós para falar de consequências, se da fila interminável delas que incessantemente vêm caminhando na nossa direcção apenas podemos ver a primeira, Significa isso que algo pode acontecer ainda, Algo, não, tudo, Não compreendo, Só porque vivemos absortos é que não reparamos que o que nos vai acontecendo deixa intacto, em cada momento, o que nos pode acontecer. Quer isso dizer que o que pode acontecer se vai regenerando constantemente, Não só se regenera como se multiplica, basta que comparemos dois dias seguidos, Nunca pensei que fosse assim, São coisas que só os angustiados conhecem bem [...] (SARAMAGO, 2007, p. 46-47).

Esse trecho importa porque ele nos ajuda a estabelecer uma relação com as discussões promovidas por Bauman (2005) sobre as identidades e a respeito das quais discorremos, quando argumenta que nossas sociedades, sobretudo pós-1945, estão assentadas em uma projeção de mundo ilusório, angustiante, inseguro, inconstante, o que acaba por refletir na própria construção de identidades, e esse "funcionamento" não foi ignorado por Saramago. Para o sociólogo,

As pessoas em busca de identidade se veem invariavelmente diante da tarefa intimidadora de "alcançar o impossivel": essa expressão genérica implica, como se sabe, tarefas que podem ser realizadas em "tempo real", mas que serão presumivelmente realizadas na plenitude do tempo - na infinitude (BAUMAN, 2005, p. 16-17).

O esforço por reconstituir as individualidades por meio do "outro", de não aceitar a resposta aparentemente tranquila para o problema colocado, "quem é esta mulher?", faz Sr. José seguir, tentar encontrar um rosto real para a mulher desconhecida. Ao "aparecer do Sol", ao final do romance, parece-nos convincente dizer que

[...] as velhas fotografias enganam muito, dão-nos a ilusão de que estamos vivos nelas, e não é certo, a pessoa para quem estamos a olhar já não existe, e ela, se pudesse ver-nos, não se reconheceria em nós, Quem será este que está a olhar para mim com cara de pena, diria (SARAMAGO, 2007, p. 180).

Todos os nomes é, ao final, a sintese dessa ação inquietante, amedrontadora, de "alcançar o impossivel", como diz Bauman.

Ajudando nesta discussão, de Jaques Guilhaumou (2009) destacamos a reflexão em torno do percurso formativo da nominação (e, portanto, da existencialização), ao qual o autor apresenta seus aspectos ontológicos, empíricos e históricos. Dito de outro modo: o nome que costumamos conferir a objetos, sujeitos e acontecimentos é um ato linguístico complexo e construido a partir de diversos acontecimentos discursivos. Essa complexidade pode, como esperamos ter discutido, ser vista no universo do Sr. José, que desde o início esteve empenhado em conhecer a mulher desconhecida, mesmo diante da impossibilidade de não ser feliz na busca, a tirar do anonimato esse ser de arquivo, percorrendo um caminho significativo de "dar nomes". Esse esforço, na história de Saramago, é um trabalho de reconstrução, que só pode acontecer em um caminho de volta, e não de ida, embora o personagem precise ir. É, logo, indo de retorno 
ao passado que o Sr. José consegue resgatar no presente um pouco da individualidade da mulher projetada. Os registros que encontra, que recolhe, que administra, estão nas memórias da senhora do rés do chão; nos arquivos da escola onde ela estudou e trabalhou; no que consegue resgatar da história de vida contada por seus próprios pais post mortem; na visita ao apartamento da mulher desconhecida. Estas informações, todas elas encontram-se fragmentadas; são como lapsos de memória, eventualidades, estilhaços de um espelho, conforme dissemos. E cada estilhaço remontado do espelho vai servindo para construir um quadro que, ao final da narrativa, como sabemos, apenas permite ao Sr. José, olhando para si, avançar para a escuridão.

Já dissemos e reiteramos: o percurso em busca da identidade também não poderia ser, na trajetória do personagem, uma estrada de traçado linear. Sr. José se encontra no Outro, por fim. A complexidade identitária está (re)afirmada nas buscas angustiantes e labirinticas da história. Somente nos labirintos é possivel vislumbrar a variedade de aspectos que se harmonizam e se contradizem na identidade do individuo "mulher desconhecida" x "Sr. José". A imagem de labirinto sintetiza, por assim dizer, a busca de si mesmo a partir do outro, representada pela saga do Sr. José pela identidade da mulher desconhecida. Alessandra Bittencourt Flach identificou esse paralelismo entre a busca da identidade do outro, representada pela busca do personagem Sr. José à mulher desconhecida, com a busca que Portugal empreende para redefinir-se enquanto país (FLACH, 2006, p.12). Não entraremos nessa discussão, embora reconheçamos a pertinência. Ela é significativa, pois mostra a força e a necessidade de lapidarmos ainda o conceito de identidade a partir de sua realização nas práticas discursivas de nosso mundo contemporâneo.

Mais do que "identidade", Todos os nomes é um livro sobre existência, sobre identidades em construção, sobre a dureza de não saber o que (se) é. Como diz o próprio Saramago, nesta espécie de chave de leitura: "Que o livro possa ser visto como uma indagação sobre a identidade, sim, mas não sobre a identidade própria. O que aqui se procura é o 'outro'" (SARAMAGO, 1997). E ele tem razão; como sempre.

\section{Duas ou três notas finais}

Em sua análise dos nomes na obra de Guimarães Rosa, Machado (2013) enfatiza a pluralidade de leituras possiveis de um texto literário; Cabral (2008) reafirma esse destino de abertura do texto nas significações dos nomes pessoais. Se pensamos nas singularidades que marcam uma individualidade como a imagem labiríntica sugerida por Saramago em Todos os nomes, então, a mesma abertura recai sobre a delimitação identitária.

O sujeito (pós)moderno é, metonimicamente, esse Sr. José, personagem em aberto, em busca, angustiado, confrontando constantemente os labirintos socioculturais dos quais faz parte, nos quais gênero, nação, tribo, raça etc., constituem suas identidades, mas não representam separadamente sua individualidade. Afinal, ao indivíduo contemporâneo são oferecidas diversas máscaras de sujeito, reforçando sua heterogeneidade, e ele as aceita amiúde: ele as usa; ele as rejeita. Tudo isso conforme vão se desenvolvendo acontecimentos de sua própria trajetória pelo mundo. Neste labirinto de possibilidades identitárias, por vezes, o sujeito contemporâneo se vê perdido, pois não há novelo de Teseu. Mesmo assim, ele sempre se reencontra, para se perder novamente e voltar a se reencontrar. Por fim, se pudermos arriscar uma resposta à pergunta: quem são os "Zés" em tempos (pós)modernos?, a partir da leitura de Todos os nomes, diríamos: somos todos!

\section{Agradecimentos}

Agradecemos aos colegas Leoné A. Barzotto e Gregório F. Dantas pela leitura atenta e sugestões apontadas. Algumas foram acatadas; outras, não. Os defeitos que porventura persistem, estes são de nossa responsabilidade. 


\section{Referências}

BAUMAN, Zygmunt. O mal-estar da pós-modernidade. Tradução de Mauro Gama e Cláudia Martinelli Gama; revisão técnica de Luís Carlos Fridman. Rio de Janeiro: Jorge Zahar, 1998.

BAUMAN, Zygmunt. Modernidade Liquida. Tradução de Plínio Dentzien. Rio de Janeiro: Jorge Zahar, 2001.

BAUMAN, Zygmunt. Identidade: entrevista a Benedetto Vecchi. Tradução de Carlos Alberto Medeiros. Rio de Janeiro: Jorge Zahar Ed., 2005.

CABRAL, João de Pina. Outros nomes, histórias cruzadas: apresentando o debate. Etnográfica, Lisboa, v. 12, n. 1, p. 5-16, maio 2008.

FLACH, Alessandra Bittencourt. Todos os nomes e a busca do inominado. Nau Literária Revista eletrônica de critica e teoria de literaturas, Porto Alegre, v. 2, p. 1-14, jul./dez. 2006. Dossiê: Saramago.

GUILHAUMOU, Jacques. Linguistica e História: percursos analíticos de acontecimentos discursivos. São Carlos: Pedro \& João Editores, 2009.

GROS, Frederic. Foucault e a questão quem somos nós? Tradução de Maria das Graças de Souza do Nascimento. Tempo Social; Rev. Sociol., São Paulo, v. 7. n. 1-2, p. 175-178, oct. 1995. Disponivel em: http://www.journals. usp.br/ts/article/viewFile/85221/88055. Acesso em: 25 abr. 2021.

HALL, Stuart. Quem precisa de identidade? SILVA, Tomaz Tadeu (org.). Identidade e diferença: a perspectiva dos estudos culturais. Petrópolis: Vozes, 2007. 133 p.

HALL, Stuart. A identidade cultural na pós-modernidade. Tradução de Tomaz Tadeu da Silva e Guaracira Lopes Louro. Rio de Janeiro: DP\&A, 2006.

LE GOFF, Jacques (dir.). O homem medieval. Tradução de Maria Jorge Vitar de Figueiredo. Lisboa: Editorial Presença, 1989.

MACHADO, Ana Maria. Recado do nome: leitura de Guimarães Rosa à luz do nome de seus personagens. São Paulo: Companhia das Letras, 2013.

MAINGUENEAU, Dominique. Discurso literário. Tradução Adail Sobral. São Paulo: Contexto, 2006.

ORLANDI, Eni P. Terra à vista: discurso do confronto: velho e no mundo. São Paulo: Cortez Editora; Campinas, SP: Editora da Unicamp, 1990

PARANHOS, Maria Cecilia Rogers. Todos os nomes, de José Saramago: um texto em dobras. Revista do Núcleo de Estudos de Literatura Portuguesa e Africana da UFF, Niterói, v. 2, n. 3, p. 99-108, nov. 2009.

SANTOS, Boaventura de Sousa. Pela mão de Alice: o social e o político na pós-modernidade. 5. ed. Porto (PT): Afrontamentos, 1996

SANTOS, Boaventura de Sousa. A critica da razão indolente: Contra o desperdício da experiência. 4. ed. São Paulo: Cortez, 2002.
SANTOS, Boaventura de Sousa. Introdução a uma ciência pós-moderna. São Paulo: Graal, 2003.

SARAMAGO, José. As intermitências da morte. Lisboa: Caminho, 2005

SARAMAGO, José. Todos os nomes. São Paulo: Companhia das Letras, 2007.

SARAMAGO, José. O presente é uma linha ténue. [Entrevista cedida al Carlos Câmara Leme. Público, 25 out. 1997. Disponivel em: http://static.publico.pt/docs/cmf/ autores/joseSaramago/todosOsNomes.htm. Acesso em: 2 ago. 2021.

SOLER, Colette. Os nomes da identidade. Tradução de Vera Pollo. Trivium: Estudos Interdisciplinares: Ciência, Tecnologia e Religião, Rio de Janeiro, v. 1, n. 1, p. 171177, 2009. Disponivel em: http://www.uva.br/trivium/ edicao1/conferencia/os-nomes-da-identidade.pdf. Acesso em: 5 set. 2021.

\section{Marcos Lúcio de Sousa Góis}

Doutor em Linguística e Língua Portuguesa pela Universidade Estadual Paulista "Júlio de Mesquita Filho" (UNESP). Lider do Grupo de Pesquisa TD: discurso, memória e violência. Professor Associado da Universidade Federal da Grande Dourados (UFGD), em Dourados, MS, Brasil.

\section{Noraci Cristiane Michel Braucks}

Mestre em Letras pela Universidade Federal da Grande Dourados (UFGD), em Dourados, MS, Brasil.

\section{Endereço de correspondência}

Marcos Lúcio de Sousa Góis

Universidade Federal da Grande Dourados

Faculdade de Comunicação, Artes e Letras

Rodovia Dourados/Itahum, Km 12 - Unidade II

79.804-970

Caixa Postal 364

Dourados, MS, Brasil

Noraci Cristiane Michel Braucks

Rua Lauro Moraes de Mattos, 1392.

Jd. Novo Horizonte, 79822-320

Dourados, MS, Brasil

Os textos deste artigo foram revisados pela Poá Comunicação e submetidos para validação do(s) autor(es) antes da publicação. 